\title{
Linearization of dynamic model of squirrel-cage induction generator wind turbine
}

\section{Citation for published version (APA):}

Ishchenko, A., Myrzik, J. M. A., \& Kling, W. L. (2007). Linearization of dynamic model of squirrel-cage induction generator wind turbine. In Proceedings of the 2007 IEEE PES General meeting 2007, 24-28 June 2007, Tampa, Florida, USA Institute of Electrical and Electronics Engineers. https://doi.org/10.1109/PES.2007.386079

DOI:

10.1109/PES.2007.386079

Document status and date:

Published: 01/01/2007

\section{Document Version:}

Publisher's PDF, also known as Version of Record (includes final page, issue and volume numbers)

\section{Please check the document version of this publication:}

- A submitted manuscript is the version of the article upon submission and before peer-review. There can be important differences between the submitted version and the official published version of record. People interested in the research are advised to contact the author for the final version of the publication, or visit the $\mathrm{DOI}$ to the publisher's website.

- The final author version and the galley proof are versions of the publication after peer review.

- The final published version features the final layout of the paper including the volume, issue and page numbers.

Link to publication

\section{General rights}

Copyright and moral rights for the publications made accessible in the public portal are retained by the authors and/or other copyright owners and it is a condition of accessing publications that users recognise and abide by the legal requirements associated with these rights.

- Users may download and print one copy of any publication from the public portal for the purpose of private study or research.

- You may not further distribute the material or use it for any profit-making activity or commercial gain

- You may freely distribute the URL identifying the publication in the public portal.

If the publication is distributed under the terms of Article 25fa of the Dutch Copyright Act, indicated by the "Taverne" license above, please follow below link for the End User Agreement:

www.tue.nl/taverne

Take down policy

If you believe that this document breaches copyright please contact us at:

openaccess@tue.nl

providing details and we will investigate your claim. 


\title{
Linearization of Dynamic Model of Squirrel- Cage Induction Generator Wind Turbine
}

\author{
A. Ishchenko, J.M.A. Myrzik, and W.L. Kling, Member, IEEE
}

\begin{abstract}
Nowadays the number of distributed generators (DG) is growing rapidly. This change will greatly influence the power system dynamics. Stability studies of large-scale power systems are becoming more and more difficult due to complexity and large variety of DG units. For example, small signal stability studies might be not so straightforward as before. A lot of questions appear: how to linearize generators with power electronics converters, in which range of operational variables will the linearized model perform well, what kind of linearization procedure to select, what are the limitations of linearized model, etc. In this paper some of these questions have been answered with an example of analytical linearization of squirrel-cage induction generator wind turbine.
\end{abstract}

Index Terms-distributed generation, squirrel-cage induction generator wind turbine, analytical linearization.

\section{INTRODUCTION}

$\mathrm{L}$ ARGE-SCALE implementation of dispersed or distributed generators (DG) leads to a gradual transition from the current 'vertically-operated power system', which is supported mainly by several big centralized generators, into a future 'horizontally-operated power system', having also a large number of small to medium-size distributed generators [1].

Dynamic models of DG are usually quite complex and nonlinear by nature. Therefore, general analysis of power system dynamics with large amount of distributed units is extremely difficult. For example, it is nearly impossible to judge whether the system is stable or not without solving differential equations using numerical integration. Obtained results are often quite subjective since they are valid only for one specific disturbance with specific magnitude.

On the opposite, theory for analysis of linear systems is well developed. One can easily make conclusion about stability just by looking on system eigenvalues. The magnitude and the nature of disturbance do not play any role in linear system stability or instability (as soon as system matrices remain unchanged). Therefore, results of analysis are general. Besides that, estimation of many system properties becomes available for instance, we can easily compute eigenvalues, singular values, participation factors, etc. The last (but not least) point is that majority of control design techniques use linear system description.

Although original system model is nonlinear, it is still possible to linearize it under certain assumptions for specific class of disturbances. However, especial care has to be taken during linearization. Results of analysis of linearized system are not general, but anyway for certain class of disturbances they are much less subjective than those obtained by numerical integration.

Besides that, linearized models can be easily used for aggregation and model reduction by mathematical methods, which are indispensable for analysis of dynamics of large-scale system. Examples of such aggregation and dynamic equivalencing are given in [2], [3], [4].

\section{PRINCIPLES OF LINEARIZATION}

Consider nonlinear state space system:

$$
\begin{aligned}
\frac{d x}{d t} & =f(x, u), \\
y & =g(x, u) .
\end{aligned}
$$

Suppose there exist state vector $x_{0}$ and input vector $u_{0}$ such that the derivative of states is equal to zero:

$$
\begin{aligned}
& \frac{d x}{d t}=f\left(x_{0}, u_{0}\right)=0, \\
& y_{0}=g\left(x_{0}, u_{0}\right) .
\end{aligned}
$$

The system (2) is called to be in equilibrium (or in steadystate), and vectors $x_{0}, u_{0}, y_{0}$ are called equilibrium point.

Let us perturb the system from equilibrium point by applying small change to input and state variables:

$$
x=x_{0}+\Delta x, \quad u=u_{0}+\Delta u, \quad y=y_{0}+\Delta y .
$$

If we substitute (3) into (1) and apply Taylor series expansion neglecting second and higher order terms, we get:

$$
\begin{gathered}
\frac{d\left(x_{0}+\Delta x\right)}{d t}=f\left(x_{0}, u_{0}\right)+\left.\frac{\partial f}{\partial x}\right|_{x_{0}, u_{0}} \Delta x+\left.\frac{\partial f}{\partial u}\right|_{x_{0}, u_{0}} \Delta u \\
y_{0}+\Delta y=g\left(x_{0}, u_{0}\right)+\left.\frac{\partial g}{\partial x}\right|_{x_{0}, u_{0}} \Delta x+\left.\frac{\partial g}{\partial u}\right|_{x_{0}, u_{0}} \Delta u
\end{gathered}
$$

Taking into account (2), we can write (4) in linear state space form:

$$
\begin{aligned}
\frac{d \Delta x}{d t} & =A \cdot \Delta x+B \cdot \Delta u, \\
\Delta y & =C \cdot \Delta x+D \cdot \Delta u,
\end{aligned}
$$

where state space matrices are equal to values of system Jacobians at operating point:

$$
A=\left.\frac{\partial f}{\partial x}\right|_{x_{0}, u_{0}}, B=\left.\frac{\partial f}{\partial u}\right|_{x_{0}, u_{0}}, C=\left.\frac{\partial g}{\partial x}\right|_{x_{0}, u_{0}}, D=\left.\frac{\partial g}{\partial u}\right|_{x_{0}, u_{0}}
$$


Generally linearization methods can be classified in three groups:

1. Methods based on system identification. The response of nonlinear system to change of inputs is either measured (in most of the cases) or simulated. After that, suitable model structure is selected - finite impulse response (FIR), autoregressive exogenous (ARX), autoregressive moving average exogenous (ARMAX), etc. In the end, parameter identification techniques are used to obtain parameters of the linear system. System identification methods are rarely used for linearization of power system components models. However, it is still possible to find some applications for that task also [5], [6].

2. Numerical perturbation. The inputs and states are numerically perturbed (changed by very small amount from the operating point value), one at a time, and the response of the system is measured by computing deviation of state derivates from zero and outputs from the operating point value. After that, states space matrices are calculated element by element using approximation of partial derivates in (6) by difference equations:

$$
\begin{aligned}
& A_{i j}=\frac{\Delta f_{i}}{\Delta x_{j}}=\frac{f_{i}\left(x_{\delta}, u_{0}\right)-f_{i}\left(x_{0}, u_{0}\right)}{x_{\delta, j}-x_{0, j}}, \\
& B_{i j}=\frac{\Delta f_{i}}{\Delta u_{j}}=\frac{f_{i}\left(x_{0}, u_{\delta}\right)-f_{i}\left(x_{0}, u_{0}\right)}{u_{\delta, j}-u_{0, j}}, \\
& C_{i j}=\frac{\Delta g_{i}}{\Delta x_{j}}=\frac{g_{i}\left(x_{\delta}, u_{0}\right)-g_{i}\left(x_{0}, u_{0}\right)}{x_{\delta, j}-x_{0, j}}, \\
& D_{i j}=\frac{\Delta g_{i}}{\Delta u_{j}}=\frac{g_{i}\left(x_{0}, u_{\delta}\right)-g_{i}\left(x_{0}, u_{0}\right)}{u_{\delta, j}-u_{0, j}},
\end{aligned}
$$

where subscript $\delta$ used for vector with perturbed $j^{\text {th }}$ component (all other components do not change) and subscript $\delta, j$ used for the value of that specific component.

Numerical perturbation is widely used in power system simulation software (for example, in PSS/E) [7]. Although this method is quick and simple, it is, as any numerical procedure, just an approximation of precise analytical solution. Precision of this approximation is dependent on the size of perturbation and numerical properties of the system. Besides, for systems with multi-scale dynamics (power system is typical example of such a system) it is very difficult to control linearization procedure. The perturbation values might need to be varied from block to block, and the selection of appropriate values might be difficult. Results of such linearization may be unpredictable. Finally, the numerical perturbation method repeats the linearization procedure each time when the operating point changes.

3. Analytical linearization. This method is based on analytical computation of system Jacobians. Usually Jacobians are determined in closed analytical form (further on, this process is referred as "linearization procedure"), and then operating point data is substituted in the Jacobians to obtain state space matrices. Although analytical linearization is more difficult to automate than numerical perturbation (this is the major disadvantage of the method), it still can be done using symbolic manipulation packages, like Symbolic Math Toolbox (in Matlab) or Mathematica. Analytical linearization is very precise (actually, the results can be used as a reference for comparison of linear models obtained by numerical perturbation) since Jacobians are derived in analytical form. Besides that, the linearization process is performed only once independent of operating point data (which is opposite to numerical perturbation). If operating point changes then new operating point data is substituted in Jacobians, and new matrices are easily obtained. Therefore, in this paper the choice has been made in favor of analytical method of linearization.

\section{DyNAMic Model OF SQUIRREL-CAGE INDUCTION GENERATOR WIND TURBINE}

The dynamic model of squirrel cage induction generator (SCIG) wind turbine is shown schematically on Figure 1.

The conventional dynamic model of induction generator is described by:

$$
\begin{aligned}
& \frac{1}{\omega} \cdot \frac{d \varphi_{d s}}{d t}=v_{d s}-R_{s} \cdot i_{d s}+\omega_{s} \cdot \varphi_{q s} \\
& \frac{1}{\omega} \cdot \frac{d \varphi_{q s}}{d t}=v_{q s}-R_{s} \cdot i_{q s}-\omega_{s} \cdot \varphi_{d s} \\
& \frac{1}{\omega} \cdot \frac{d \varphi_{d r}}{d t}=v_{d r}-R_{r} \cdot i_{d r}+\left(\omega_{s}-\omega_{r}\right) \cdot \varphi_{q r} \\
& \frac{1}{\omega} \cdot \frac{d \varphi_{q r}}{d t}=v_{q r}-R_{r} \cdot i_{q r}-\left(\omega_{s}-\omega_{r}\right) \cdot \varphi_{d r}
\end{aligned}
$$

where all quantities are referred to the stator side and taken in p.u. (except $\omega$, which is in rad/s). $\omega_{s}$ is speed of synchronously rotating reference frame ( $\omega_{s}=1$ p.u.). The currents and fluxes are related by the following equations:

$$
\begin{aligned}
& i_{d s}=\frac{\varphi_{d s}-\varphi_{m d}}{L_{l s}}, \quad i_{q s}=\frac{\varphi_{q s}-\varphi_{m q}}{L_{l s}}, \\
& i_{d r}=\frac{\varphi_{d r}-\varphi_{m d}}{L_{l r}}, \quad i_{q r}=\frac{\varphi_{q r}-\varphi_{m q}}{L_{l r}} .
\end{aligned}
$$

And, finally, mutual fluxes are equal to:

$$
\varphi_{m d}=L_{a d} \cdot\left(\frac{\varphi_{d s}}{L_{l s}}+\frac{\varphi_{d r}}{L_{l r}}\right), \quad \varphi_{m q}=L_{a q} \cdot\left(\frac{\varphi_{q s}}{L_{l s}}+\frac{\varphi_{q r}}{L_{l r}}\right),
$$

with armature inductances $L_{a d}$ and $L_{a q}$ (in case of equal distribution of windings in space):

$$
L_{a d}=L_{a q}=\frac{L_{l r} \cdot L_{l s} \cdot L_{m}}{L_{\sigma}}=\frac{L_{l r} \cdot L_{l s} \cdot L_{m}}{L_{l r} \cdot L_{l s}+L_{l s} \cdot L_{m}+L_{l r} \cdot L_{m}} .
$$




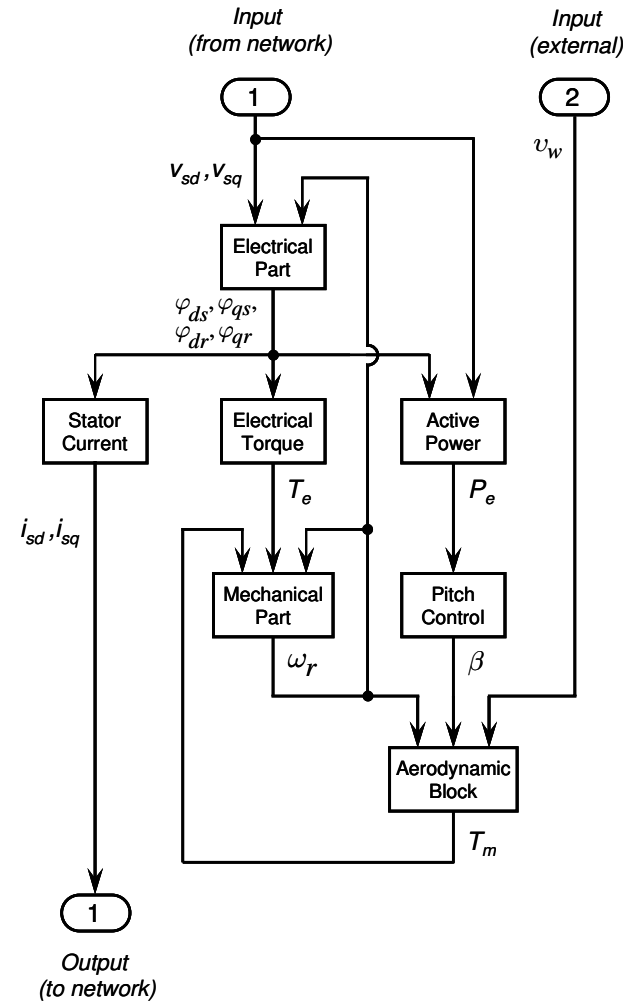

Figure 1. Structure of SCIG wind turbine dynamic model

Equations (8) - (11) give the description of electrical part of SCIG. Further, the electrical part can be completely written in terms of either fluxes or currents by eliminating corresponding variables. In this case fluxes are selected to be state variables since this is more general representation, which allows also introduction of saturation in the model (although this feature has not been used in this paper). The resulting equations for Electrical Part (on Figure 1) look as follows:

$$
\begin{aligned}
& \frac{1}{\omega} \frac{d \varphi}{d t}=\left[\begin{array}{cccc}
-R_{s} \frac{L_{r}}{L_{\sigma}} & \omega_{s} & R_{s} \frac{L_{m}}{L_{\sigma}} & 0 \\
-\omega_{s} & -R_{s} \frac{L_{r}}{L_{\sigma}} & 0 & R_{s} \frac{L_{m}}{L_{\sigma}} \\
R_{r} \frac{L_{m}}{L_{\sigma}} & 0 & -R_{r} \frac{L_{s}}{L_{\sigma}} & \omega_{s}-\omega_{r} \\
0 & R_{r} \frac{L_{m}}{L_{\sigma}} & -\left(\omega_{s}-\omega_{r}\right) & -R_{r} \frac{L_{s}}{L_{\sigma}}
\end{array}\right] \cdot \varphi+v \\
& \boldsymbol{\varphi}=\left[\begin{array}{llll}
\varphi_{d s} & \varphi_{q s} & \varphi_{d r} & \varphi_{q r}
\end{array}\right]^{T}, \quad v=\left[\begin{array}{llll}
v_{d s} & v_{q s} & v_{d r} & v_{q r}
\end{array}\right]^{T}, \\
& L_{s}=L_{l s}+L_{m}, \quad L_{r}=L_{l r}+L_{m} \text {. }
\end{aligned}
$$

For SCIG $v_{d r}$ and $v_{q r}$ are equal to zero since the rotor windings are short-circuited.

Electrical Torque block is described by:

$$
T_{e}=\varphi_{d s} i_{q s}-\varphi_{q s} i_{d s}=\frac{L_{m}}{L_{\sigma}} \cdot\left(\varphi_{d r} \varphi_{q s}-\varphi_{q r} \varphi_{d s}\right)
$$

Equations for Stator Current block can also be derived from $(9)-(11)$ :

$$
i=\frac{1}{L_{\sigma}} \cdot\left[\begin{array}{cccc}
L_{r} & 0 & -L_{m} & 0 \\
0 & L_{r} & 0 & -L_{m} \\
-L_{m} & 0 & L_{s} & 0 \\
0 & -L_{m} & 0 & L_{s}
\end{array}\right] \cdot \varphi,
$$

where $i=\left[\begin{array}{llll}i_{d s} & i_{q s} & i_{d r} & i_{q r}\end{array}\right]^{T}$.

Stator current components $i_{d s}$ and $i_{q s}$ serve as outputs to the network, while rotor current components $i_{d s}$ and $i_{q s}$ are just not used further in the model.

Equation for Active Power block:

$$
\begin{aligned}
& P_{e}=v_{d s} i_{d s}+v_{q s} i_{q s}= \\
& =\frac{1}{L_{\sigma}}\left[\left(L_{r} \varphi_{d s}-L_{m} \varphi_{d r}\right) \cdot v_{d s}+\left(L_{r} \varphi_{q s}-L_{m} \varphi_{q r}\right) \cdot v_{q s}\right]
\end{aligned}
$$

Differential equation representing Mechanical Part of SCIG:

$$
\frac{d \omega_{r}}{d t}=\frac{1}{2 H} \cdot\left(T_{e}-T_{m}-F \omega_{r}\right) .
$$

Structural diagram of Pitch Control block is shown on Figure 2, while mathematical description is given below:

$$
\begin{gathered}
\beta=K_{p} \cdot\left(P_{\text {meas }}-P_{\text {ref }}\right)+K_{i} \cdot \int\left(P_{\text {meas }}-P_{\text {ref }}\right) d t, \\
0 \leq \beta_{i} \leq \beta_{\max }, \quad 0 \leq \beta \leq \beta_{\max }, \\
\text { PitchRate }_{\min } \leq \frac{d \beta}{d t} \leq \text { PitchRate }_{\max } .
\end{gathered}
$$

Pitch control contains a proportional-integral (PI) controller, which is used to limit the electric output power of the turbine. It is necessary when the measured electric output power of the turbine is above its rated value. In such situation PI controller increases the pitch angle to decrease generated power. In other situations saturation block prevent operation of the controller. Pitch rate limiter represents limits of servo mechanism changing pitch angle.

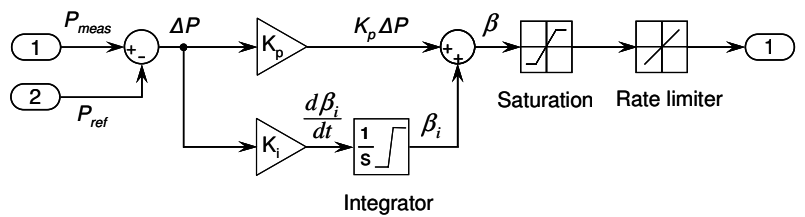

Figure 2. Structure of Pitch Control block

In the model it is assumed that power measurement can be taken into account in ideal form (i.e. $P_{\text {meas }}=P_{e}$ ).

Integrator with saturation is used in pitch control block to prevent integral wind up. When the control limits are reached, we have to stop integrating. Otherwise integrator will continue to integrate, and this accumulated charge must be removed later, resulting in substantial overshoot. Integrator with saturation helps to avoid this problem.

The Aerodynamic Block represents the steady-state relationship between wind speed $(\mathrm{m} / \mathrm{s})$ and mechanical power of 
the turbine $P_{\text {mtur }}$ (written in p.u. of turbine):

$$
P_{\text {m tur }}=\frac{c_{p}}{c_{\text {p nom }}} \cdot \frac{v_{w}^{3}}{v_{\text {wbase }}^{3}} \text {. }
$$

In this simplified relationship the dynamic stall, wind shear and tower shadow effects are neglected. Under certain conditions these approximations are valid for studies on the system level. The block has three inputs (wind speed $v_{w}$, rotor speed of generator $\omega_{r}$ and pitch angle $\beta$ ) and one output (mechanical torque of the turbine $T_{m}$ ). Power coefficient $c_{p}$, which shows the ratio between the power contained in the wind and the power extracted from it by the turbine, is defined as:

$$
c_{p}=c_{1} \cdot\left(\frac{c_{2}}{\lambda_{i}}-c_{3} \beta-c_{4}\right) \cdot e^{\left(-\frac{c_{5}}{\lambda_{i}}\right)}+c_{6} \lambda
$$

where

$$
\lambda=\lambda_{\text {nom }} \cdot \frac{v_{\text {wbase }}}{\omega_{\text {turnom }}} \cdot \frac{\omega_{r}}{v_{w}}, \quad \lambda_{i}=\frac{1}{\frac{1}{\lambda+0.08 \beta}-\frac{0.035}{\beta^{3}+1}} .
$$

Finally, after transformation of mechanical power from p.u. of turbine to p.u. of generator (from $P_{m}$ tur to $P_{m}$ ) and division by rotor speed of generator $\omega_{r}$, we can get the mechanical torque $T_{m}$ (which serves as an input to the mechanical part of generator):

$$
P_{m}=\frac{P_{\text {wind base }} \cdot P_{\text {tur nom }}}{S_{n o m}} \cdot P_{m \text { tur }}, \quad T_{m}=-\frac{P_{m}}{\omega_{r}} .
$$

\section{LINEARIZATION OF DYNAMIC MODEL OF SCIG}

The linearization of 1.5 MW SCIG model was performed analytically block by block, and after that, the state space matrices were obtained for the complete SCIG model. Responses of original and linearized blocks and of the whole generator model were compared for voltage dip to 0.6 p.u. on the terminals of generator (made by applying distant three-phase fault).

Linearization of Electrical Torque block described by (12) leads to the following equation:

$$
\begin{aligned}
\Delta T_{e}= & \frac{L_{m}}{L_{\sigma}} \cdot\left(\varphi_{d r 0} \cdot \Delta \varphi_{q s}-\varphi_{q r 0} \cdot \Delta \varphi_{d s}+\right. \\
& \left.+\varphi_{q s 0} \cdot \Delta \varphi_{d r}-\varphi_{d s 0} \cdot \Delta \varphi_{q r}\right) .
\end{aligned}
$$

Responses to the disturbance of original and linearized relationships for electrical torque are compared on Figure 3.

Stator Current block is already in linear form so the description stays the same as in (13).

Linearized equation for Active Power block (14) is presented below:

$$
\begin{aligned}
\Delta P_{e}=\frac{1}{L_{\sigma}} \cdot & {\left[L_{r}\left(v_{d s 0} \cdot \Delta \varphi_{d s}+v_{q s 0} \cdot \Delta \varphi_{q s}+\varphi_{d s 0} \cdot \Delta v_{d s}+\varphi_{q s 0} \cdot \Delta v_{q s}\right)-\right.} \\
& \left.-L_{m}\left(v_{d s 0} \cdot \Delta \varphi_{d r}+v_{q s 0} \cdot \Delta \varphi_{q r}+\varphi_{d r 0} \cdot \Delta v_{d s}+\varphi_{q r 0} \cdot \Delta v_{q s}\right)\right]
\end{aligned}
$$

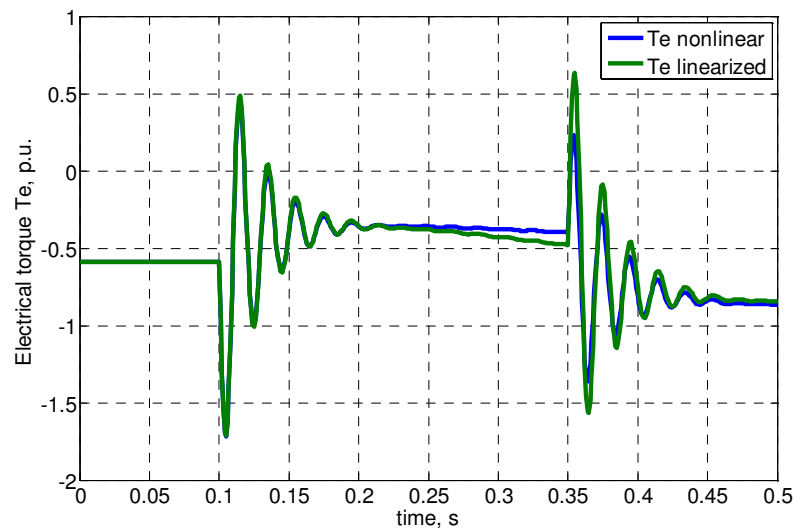

Figure 3. Nonlinear and linearized electrical torque during voltage dip

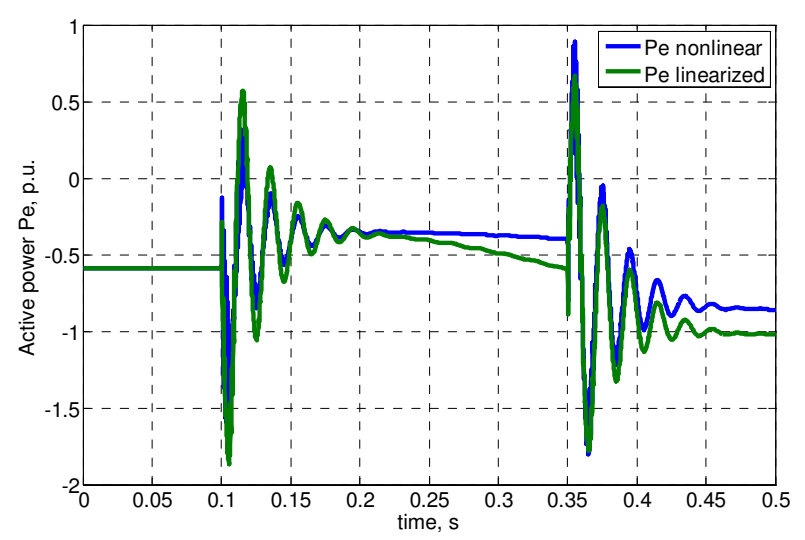

Figure 4. Nonlinear and linearized active power during voltage dip

The response of linearized and nonlinear active power equations to voltage dip is shown on Figure 4 (active power is expressed in p.u. of nominal apparent power).

Electrical Part of SCIG after linearization looks as follows:

$$
\begin{aligned}
& \frac{1}{\omega} \cdot \frac{d}{d t}\left[\begin{array}{c}
\Delta \varphi_{s d} \\
\Delta \varphi_{s q} \\
\Delta \varphi_{r d} \\
\Delta \varphi_{r q}
\end{array}\right]=A_{1} \times\left[\begin{array}{c}
\Delta \varphi_{s d} \\
\Delta \varphi_{s q} \\
\Delta \varphi_{r d} \\
\Delta \varphi_{r q}
\end{array}\right]+B_{1} \times\left[\begin{array}{c}
\Delta v_{s d} \\
\Delta v_{s q} \\
\Delta v_{r d} \\
\Delta v_{r q} \\
\Delta \omega_{r}
\end{array}\right], \\
& A_{1}=\left[\begin{array}{cccc}
-R_{s} \frac{L_{r}}{L_{\sigma}} & 1 & R_{s} \frac{L_{m}}{L_{\sigma}} & 0 \\
-1 & -R_{s} \frac{L_{r}}{L_{\sigma}} & 0 & R_{s} \frac{L_{m}}{L_{\sigma}} \\
R_{r} \frac{L_{m}}{L_{\sigma}} & 0 & -R_{r} \frac{L_{s}}{L_{\sigma}} & 1-\omega_{r 0} \\
0 & R_{r} \frac{L_{m}}{L_{\sigma}} & -\left(1-\omega_{r 0}\right) & -R_{r} \frac{L_{s}}{L_{\sigma}}
\end{array}\right],
\end{aligned}
$$

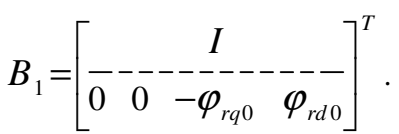


Linearization of the Aerodynamic Block ((17) - (19)) gives the following results:

$$
\Delta T_{m}=k_{1} \cdot \Delta \omega_{r}+k_{2} \cdot \Delta \beta+k_{3} \cdot \Delta v_{w},
$$

where coefficients $k_{1}, k_{2}$ and $k_{3}$ are equal to:

$$
\begin{gathered}
k_{1}=\frac{P_{\text {wind base }} P_{\text {tur nom }}}{S_{\text {nom }} c_{p \text { nom }} v_{\text {wbase }}^{3}} \cdot \frac{c_{p 0} \cdot v_{w 0}^{3}}{\omega_{r 0}^{2}}, \\
k_{2}=-\frac{P_{\text {wind base }} P_{\text {tur nom }}}{S_{\text {nom }} c_{p \text { nom }} v_{\text {wbase }}^{3}} \cdot \frac{3 c_{p 0} \cdot v_{w 0}^{2}}{\omega_{r 0}}, \\
k_{3}=\frac{P_{\text {wind base }} P_{\text {tur nom }}}{S_{\text {nom }} c_{\text {p nom }} v_{\text {wbase }}^{3}} \cdot \frac{c_{1} c_{3} e}{\omega_{r 0}^{\left(-\frac{c_{5}}{\lambda_{i 0}}\right)} \cdot v_{w 0}^{3}} .
\end{gathered}
$$

$c_{p 0}$ and $\lambda_{i 0}$ are functions of operating point variables $\omega_{r 0}$, $\beta_{0}, v_{w 0}$ :

$$
\begin{gathered}
c_{p 0}=c_{1} \cdot\left(\frac{c_{2}}{\lambda_{i 0}}-c_{3} \beta_{0}-c_{4}\right) \cdot e^{\left(-\frac{c_{5}}{\lambda_{i 0}}\right)}+c_{6} \lambda_{0}, \\
\lambda_{i 0}=\frac{1}{\frac{1}{\lambda_{0}+0.08 \beta_{0}}-\frac{0.035}{\beta_{0}^{3}+1}} \\
\lambda_{0}=\lambda_{\text {nom }} \cdot \frac{v_{\text {wbase }}}{\omega_{\text {turnom }}} \cdot \frac{\omega_{r 0}}{v_{w 0}}
\end{gathered}
$$

Because of highly nonlinear nature of the block the results of linearization must be checked carefully. The most important point to check is whether the output of linearized block is sufficiently close to that of nonlinear one under variation of inputs.

First, the operating point was selected: $\omega_{r 0}=1.002$ p.u., $\beta_{0}=10^{\circ}, v_{w 0}=8 \mathrm{~m} / \mathrm{s}, T_{m 0}=-0.301$ p.u. Selection of this operating point makes the matching better for wider range of inputs changes as illustrated on Figures 5-7 (the calculation was done varying one input, while fixing the others).

For this specific operating point the response of linear model is close to the original one under quite large variation of inputs (this also was checked by variation of not only one, but several inputs at the same time). However, since the disturbance, for which further analysis has been done is voltage dip and since we keep wind speed constant, it can be assumed that the pitch angle will be equal or nearly equal to zero. We can prove correctness of this assumption also by noting from Figure 4 that active power does not go much higher the reference value (in this example 0.9 p.u. of nominal apparent power). It can be observed from Figure 6 that the matching for pitch angle around zero for specified $\beta_{0}=10^{\circ}$ is not really good. Therefore, the operating point was updated and new value of $\beta_{0}=$ $0^{\circ}$ was set. Such a choice gives good matching between nonlinear and linearized aerodynamic blocks only for the val-

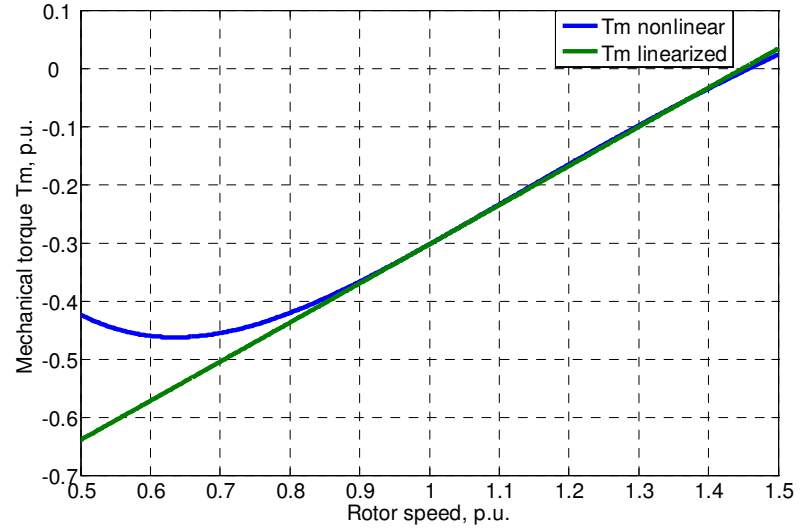

Figure 5. Original and linear mechanical torques under variation of rotor speed

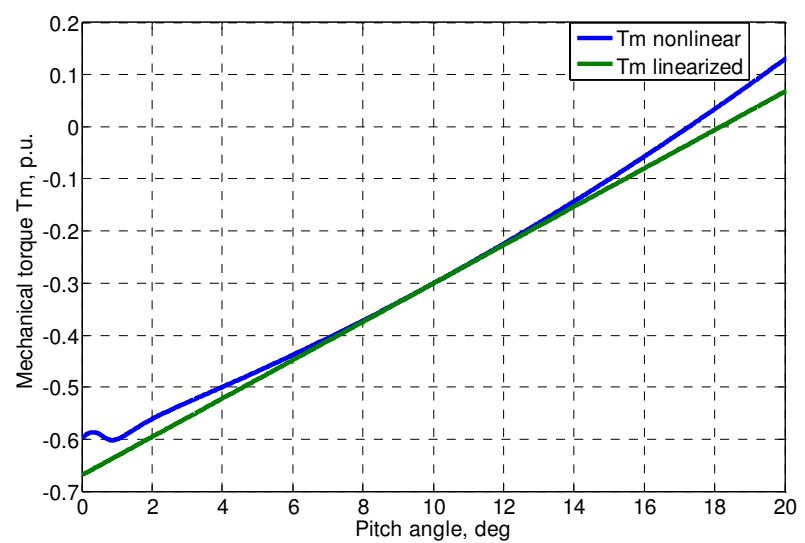

Figure 6. Original and linear mechanical torques under variation of pitch angle

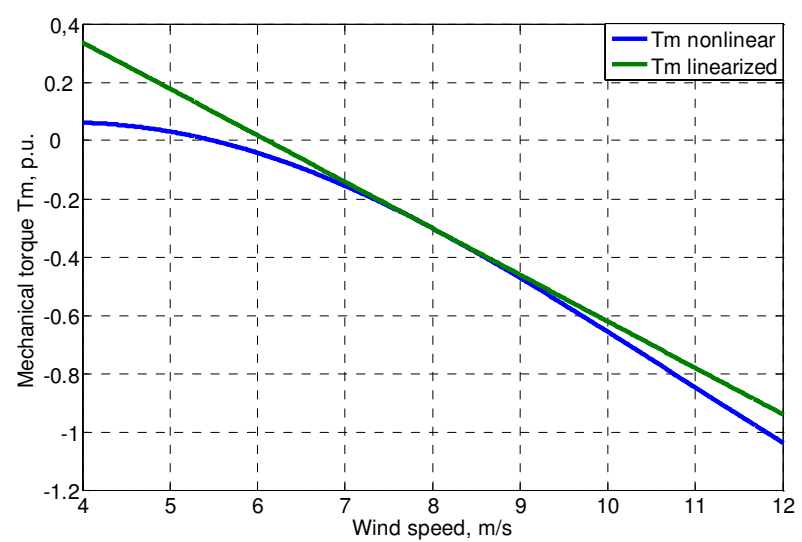

Figure 7. Original and linear mechanical torques under variation of wind speed

ues of pitch angles in the close neighborhood of zero.

The most ambiguous part of SCIG linearization is in the Pitch Control block (see (16) and Figure 2). The difficulty appears due to the fact that for wind speeds below nominal the pitch control is saturated, i.e. the pitch angle is limited to zero and the integrator is disconnected to prevent wind up. At the same time, for wind speeds above nominal the pitch control acts as usual PI controller. Therefore, two linear models for 
SCIG have to be created: first - for operation of generator with saturated pitch control, and second - for operation of generator with linear pitch control. For the first model the controller is completely removed and pitch angle is defined as an external input (constant) to linearized SCIG model. For the second model nonlinearities (saturation, rate limiter and saturation in the integrator) are simply removed from the pitch controller. The SCIG model structure stays the same as on Figure 1.

Use of model with enabled pitch control for analysis of wind turbine behavior during low wind speeds can lead to erroneous results. Figure 8 illustrates this fact. The pitch angle obtained with the use of original nonlinear model is equal to zero, while the model with pitch control is trying to increase generated power (although it is not possible from the physical point of view) by driving pitch angle to negative value. Removal of pitch control block and definition of pitch angle as external input equal to zero help to avoid such situation.

The linear expression for Mechanical Part of SCIG can be obtained by substitution of linearized equations for electrical and mechanical torque ((20) and (22), respectively) in (15):

$$
\begin{aligned}
\frac{d \Delta \omega_{r}}{d t}= & \frac{1}{2 \cdot H} \cdot\left[\Delta T_{e}\left(\Delta \varphi_{d s}, \Delta \varphi_{q s}, \Delta \varphi_{d r}, \Delta \varphi_{q r}\right)-\right. \\
& \left.-T_{m}\left(\Delta \omega_{r}, \Delta \beta, \Delta v_{w}\right)-F \cdot \Delta \omega_{r}\right] .
\end{aligned}
$$

The response of original and linearized mechanical part during voltage dip is shown on Figure 9.

Finally, linearized blocks were combined to create complete linear model of the whole SCIG. The state-space model with pitch control enabled is described in analytical form by the following expressions (the matrices are shown in details on the last page):

$$
\begin{gathered}
\frac{d \Delta x_{S C I G}^{\text {pitch }}}{d t}=A_{S C I G}^{\text {pitch }} \cdot \Delta x_{S C I G}^{\text {pitch }}+B_{S C I G}^{\text {pitch }} \cdot \Delta u_{S C I G}^{\text {pitch }} \\
\Delta y_{S C I G}^{\text {pitch }}=C_{S C I G}^{\text {pitch }} \cdot \Delta x_{S C I G}^{\text {pitch }}+D_{S C I G}^{\text {pitch }} \cdot \Delta u_{S C I G}^{\text {pitch }}
\end{gathered},
$$

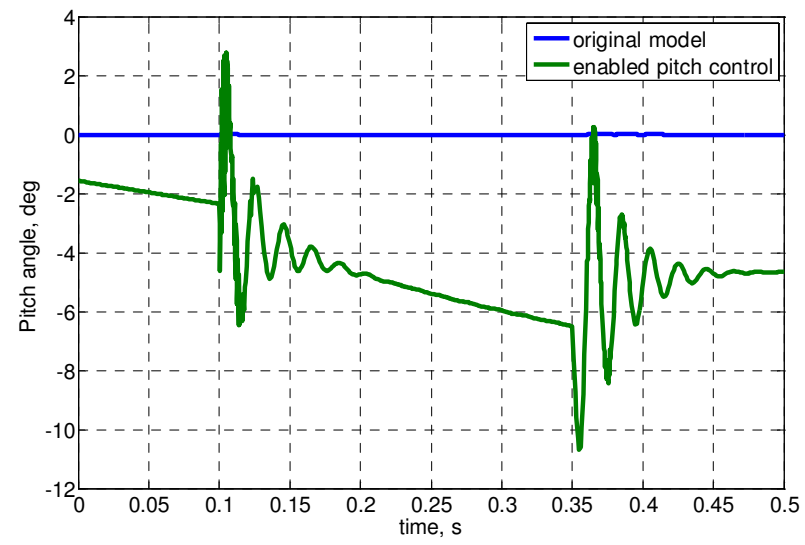

Figure 8. Pitch angle of original model and model with enabled pitch control during voltage dip where the vectors of states, inputs and outputs are defined as:

$$
\begin{aligned}
& \Delta x_{S C I G}^{\text {pitch }}=\left[\begin{array}{llllll}
\Delta \varphi_{s d} & \Delta \varphi_{s q} & \Delta \varphi_{r d} & \Delta \varphi_{r q} & \Delta \omega_{r} & \Delta \beta_{i}
\end{array}\right], \\
& \Delta u_{S C I G}^{\text {pitch }}=\left[\begin{array}{lllll}
\Delta v_{s d} & \Delta v_{s q} & \Delta v_{r d} & \Delta v_{r q} & \Delta v_{w}
\end{array}\right], \\
& \Delta y_{S C I G}^{p i t c h}=\left[\begin{array}{ll}
\Delta i_{s d} & \Delta i_{s q}
\end{array}\right] \text {. }
\end{aligned}
$$

The model without pitch control is slightly different (see matrices on the last page):

$$
\begin{aligned}
\frac{d \Delta x_{S C I G}}{d t} & =A \cdot \Delta x_{S C I G}+B \cdot \Delta u_{S C I G}, \\
\Delta y_{S C I G} & =C \cdot \Delta x_{S C I G}+D \cdot \Delta u_{S C I G}
\end{aligned}
$$

where the vectors of states, inputs and outputs are defined as:

$$
\begin{aligned}
& \Delta x_{S C I G}=\left[\begin{array}{lllll}
\Delta \varphi_{s d} & \Delta \varphi_{s q} & \Delta \varphi_{r d} & \Delta \varphi_{r q} & \Delta \omega_{r}
\end{array}\right], \\
& \Delta u_{S C I G}=\left[\begin{array}{llllll}
\Delta v_{s d} & \Delta v_{s q} & \Delta v_{r d} & \Delta v_{r q} & \Delta v_{w} & \Delta \beta_{i}
\end{array}\right], \\
& \Delta y_{S C I G}=\left[\begin{array}{ll}
\Delta i_{s d} & \Delta i_{s q}
\end{array}\right] \text {. }
\end{aligned}
$$

Voltage dip to 0.6 p.u. was simulated and responses of original and linearized models of the whole SCIG (stator currents) were compared (see Figure 10).

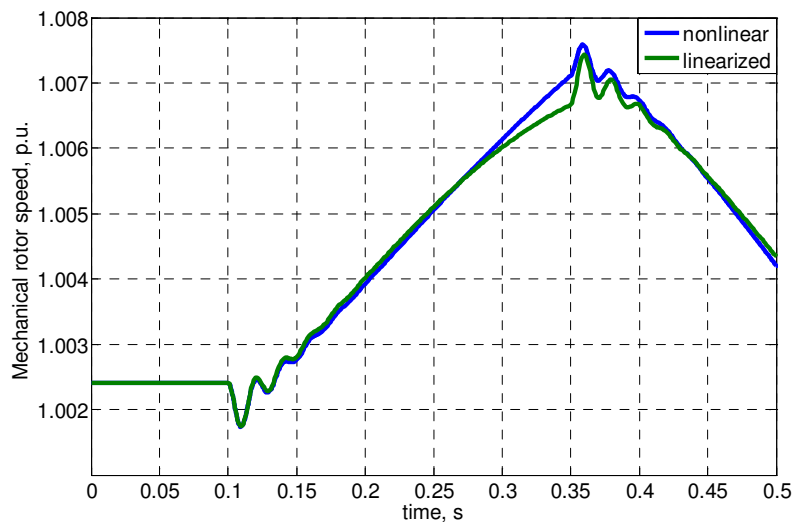

Figure 9. Original and linear generator rotor speed during voltage dip

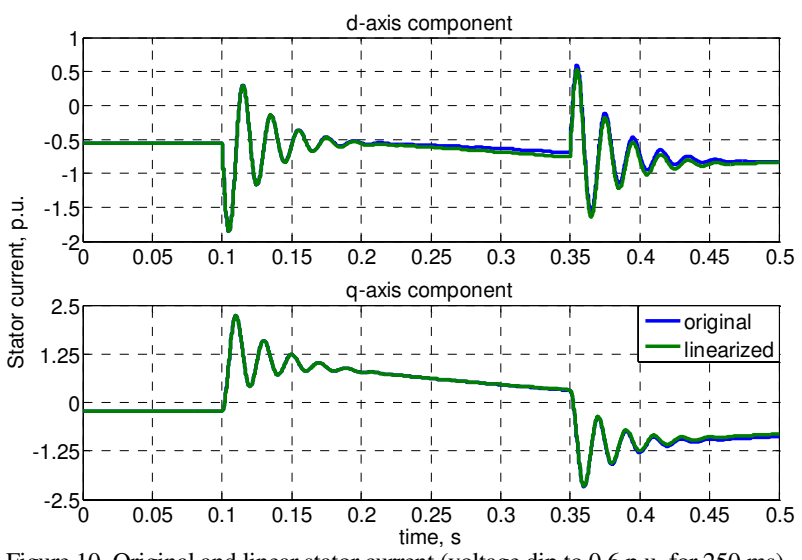

Figure 10. Original and linear stator current (voltage dip to 0.6 p.u. for $250 \mathrm{~ms}$ ) 


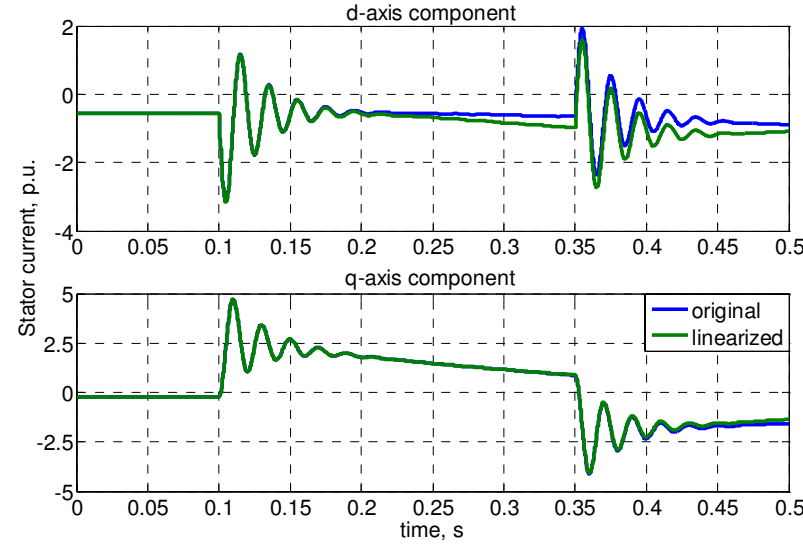

Figure 11. Original and linear stator current (voltage dip to 0.1 p.u. for $250 \mathrm{~ms}$ )

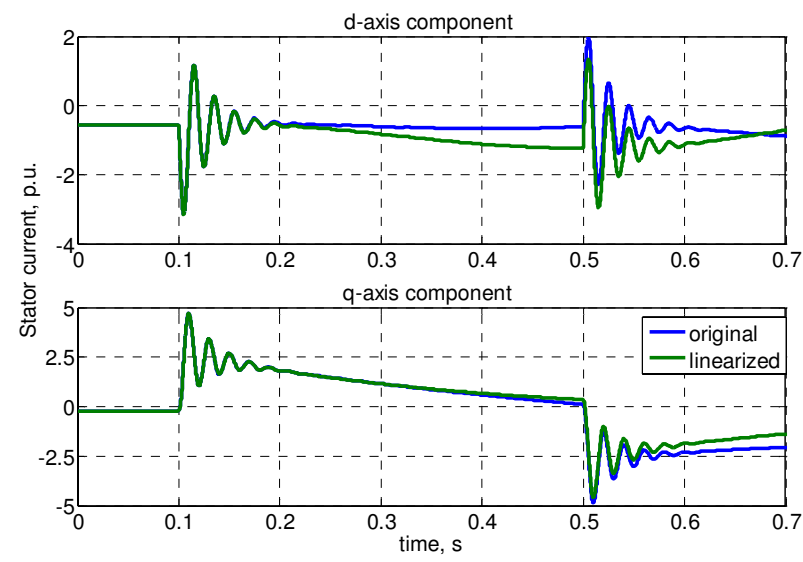

Figure 12. Original and linear stator current (voltage dip to 0.1 p.u. for $400 \mathrm{~ms}$ )

The good agreement of these curves is extremely important since stator currents are the outputs of the whole SCIG model that interface the generator model with the model of the rest of the network. Results of simulations for larger and longer voltage dips are shown on Figures 11 and 12. As it can be seen from the figures, the differences in responses of original and linearized SCIG are insignificant, and therefore linear model adequately represents dynamics of SCIG for such type of disturbances.

\section{CONCLUSIONS}

This paper illustrates how analytical linearization can be applied for obtaining linearized model of SCIG wind turbine. It has been shown that linearization has to be performed carefully, always taking into account operational conditions, under which dynamic behavior will be analyzed.

Linearized model in analytical form has the advantage that it can be used not only for one specific operating point, but can be easily modified for any operating point. Construction of the whole power system model in linear form (using linearized models of elements as building blocks) also becomes possible and straightforward. Linear models are indispensable for large variety of analysis and design tasks, such as small-signal stability and subsynchronous resonance studies, control design, model reduction, etc.

\section{APPENDIX I: DESCRIPTION OF SUBSCRIPTS}

$d, q \quad-\mathrm{d}$-axis and q-axis quantity respectively,

$r, s \quad-$ rotor and stator quantity,

$l, m \quad-$ leakage and magnetizing inductance,

$0 \quad-$ operating point variable,

\section{APPENDIX II: DESCRIPTION OF VARIABLES}

$\begin{array}{ll}T_{m}, T_{e} & - \text { mechanical and electrical torque, } \\ R, L & - \text { resistance and inductance, } \\ v, i, \varphi & - \text { voltage, current and flux linkage, } \\ \omega_{r} & - \text { generator rotor speed, } \\ \beta & - \text { pitch angle, } \\ v_{w} & - \text { wind speed. }\end{array}$

\section{ACKNOWLEDGEMENT}

This research has been performed within the framework of the research program 'Intelligent Power Systems' that is supported financially by Senter Novem. Senter Novem is an agency of the Dutch Ministry of Economic Affairs.

\section{REFERENCES}

[1] M. Reza, P.H. Schavemaker, W.L. Kling, L. van der Sluis, "A research program on intelligent power systems: self controlling and self adapting power systems equipped to deal with the structural changes in the generation and the way of consumption," CIRED 2003, Barcelona, Spain, Paper: 4.70, May 2003.

[2] D. Chaniotis, M.A. Pai, "Model reduction in power systems using Krylov subspace methods," IEEE Trans. on Power Systems, Vol. 20, No. 2, pp. 888-894, May 2005.

[3] A. Ishchenko, A. Jokic, J.M.A. Myrzik, W.L. Kling, "Dynamic reduction of distribution networks with dispersed generation," International Conference on Future Power Systems, Amsterdam, Netherlands, November 2005.

[4] A. Ishchenko, J.M.A. Myrzik, W.L. Kling, "Dynamic equivalencing of distribution networks with dispersed generation," IEEE PES General Meeting, Montreal, Canada, June 2006.

[5] J. Persson, "Linear models of nonlinear power system components," Licentiate Thesis, KTH, Stockholm, Sweden, 2002.

[6] J. Persson, "Bandwidth-reduced linear models of non-continuous power system components," PhD Thesis, KTH, Stockholm, Sweden, 2006.

[7] J.G. Slootweg, J. Persson, A.M. van Voorden, G.C. Paap, W.L. Kling, "A study of the eigenvalue analysis capabilities of power system dynamics simulation software," Power Systems Computation Conference 2002, Sevilla, Spain, June 2002.

\section{BIOGRAPHIES}

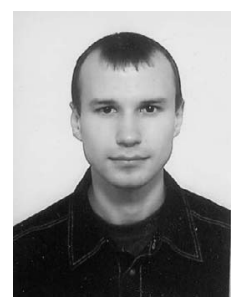

Anton Ishchenko was born in Krasnodar, Russia in 1980. He received MSc. in Electrical Engineering from the Kuban State Technological University, Russia in 2002. In 2001 he was honored with Russian Academy of Electrotechnical Sciences Award for outstanding student's paper in the area of "Power and Electrical Engineering". At the same year he received Russian Ministry of Education Award for outstanding student in the area of technical science. In August 2003 he joined the Electrical Power Systems group, Technical University of Eindhoven as PhD student. His major fields of interest are: renewable energy sources, control systems, power system protection and emergency controls, power system transients and stability. 


$$
\begin{aligned}
& A_{S C I G}^{\text {pich }}=\left[\begin{array}{cccccc}
-\omega R_{s} \frac{L_{r}}{L_{\sigma}} & \omega & \omega R_{s} \frac{L_{m}}{L_{\sigma}} & 0 & 0 & 0 \\
-\omega & -\omega R_{s} \frac{L_{r}}{L_{\sigma}} & 0 & \omega R_{s} \frac{L_{m}}{L_{\sigma}} & 0 & 0 \\
\omega R_{r} \frac{L_{m}}{L_{\sigma}} & 0 & -\omega R_{r} \frac{L_{s}}{L_{\sigma}} & \omega\left(1-\omega_{r 0}\right) & -\omega \varphi_{r q 0} & 0 \\
0 & \omega R_{r} \frac{L_{m}}{L_{\sigma}} & -\omega\left(1-\omega_{r 0}\right) & -\omega R_{r} \frac{L_{s}}{L_{\sigma}} & \omega \varphi_{r d 0} & 0 \\
a_{1} & a_{2} & a_{3} & a_{4} & \frac{-k_{1}-F}{2 H}-\frac{k_{2}}{2 H}
\end{array}\right], \begin{array}{c}
a_{1}=\frac{1}{2 H L_{\sigma}}\left(-L_{m} \varphi_{r q 0}-K_{i} k_{2} L_{r} v_{s d 0}\right), \\
a_{2}\left(L_{m} \varphi_{r d 0}+K_{i} k_{2} L_{r} v_{s q 0}\right), \\
a_{3}=\frac{L_{m}}{2 H L_{\sigma}}\left(\varphi_{s q 0}-K_{i} k_{2} v_{s d 0}\right), \\
a_{4}=\frac{L_{m}}{2 H L_{\sigma}}\left(-\varphi_{s d 0}-K_{i} k_{2} v_{s q 0}\right) .
\end{array} \\
& {\left[\begin{array}{llllll}
-K_{i} \frac{L_{r}}{L_{\sigma}} v_{s d 0}-K_{i} \frac{L_{r}}{L_{\sigma}} v_{s q 0} & K_{i} \frac{L_{m}}{L_{\sigma}} v_{s d 0} & K_{i} \frac{L_{m}}{L_{\sigma}} v_{s q 0} & 0 & 0
\end{array}\right]}
\end{aligned}
$$

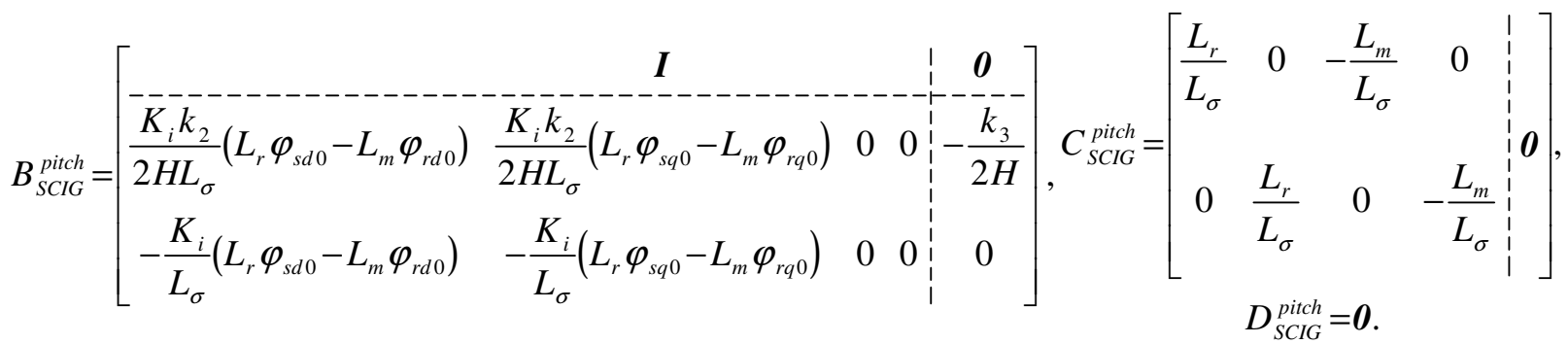

$$
\begin{aligned}
& A_{S C I G}=\left[\begin{array}{ccccc}
-\omega R_{s} \frac{L_{r}}{L_{\sigma}} & \omega & \omega R_{s} \frac{L_{m}}{L_{\sigma}} & 0 & 0 \\
-\omega & -\omega R_{s} \frac{L_{r}}{L_{\sigma}} & 0 & \omega R_{s} \frac{L_{m}}{L_{\sigma}} & 0 \\
\omega R_{r} \frac{L_{m}}{L_{\sigma}} & 0 & -\omega R_{r} \frac{L_{s}}{L_{\sigma}} & \omega\left(1-\omega_{r 0}\right) & -\omega \varphi_{r q 0} \\
0 & \omega R_{r} \frac{L_{m}}{L_{\sigma}} & -\omega\left(1-\omega_{r 0}\right) & -\omega R_{r} \frac{L_{s}}{L_{\sigma}} & \omega \varphi_{r d 0} \\
-\frac{L_{m}}{2 H L_{\sigma}} \varphi_{r q 0} & \frac{L_{m}}{2 H L_{\sigma}} \varphi_{r d 0} & \frac{L_{m}}{2 H L_{\sigma}} \varphi_{s q 0} & -\frac{L_{m}}{2 H L_{\sigma}} \varphi_{s d 0} & \frac{-k_{1}-F}{2 H}
\end{array}\right], \quad B_{S C I G}=\left[\begin{array}{ccc}
\boldsymbol{I} & 0 \\
\hdashline & -\frac{k_{3}}{2 H} & -\frac{k_{2}}{2 H}
\end{array}\right],
\end{aligned}
$$

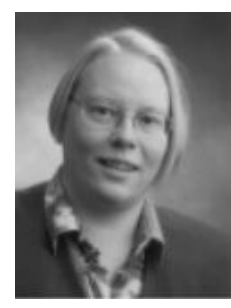

Johanna M.A. Myrzik was born in Darmstadt, Germany in 1966. She received her MSc. in Electrical Engineering from the Darmstadt University of Technology, Germany in 1992. From 1993 to 1995 she worked as a researcher at the Institute for Solar Energy Supply Technology (ISET e.V.) in Kassel, Germany. In 1995 Mrs. Myrzik joined the Kassel University, where she finished her $\mathrm{PhD}$ thesis in the field of solar inverter topologies in 2000. Since 2000, Mrs. Myrzik is with the Eindhoven University of Technology, the Netherlands. In 2002, she became an assistant professor in the field of distributed generation. Her fields of interests are: power electronics, renewable energy, distributed generation, electrical power supply.

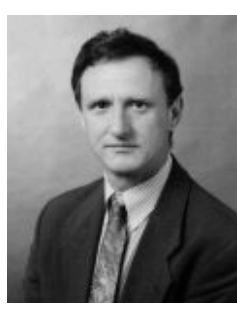

Wil L. Kling (M'95) was born in Heesch, The Netherlands in 1950 . He received the M.Sc. degree in electrical engineering from the Technical University of Eindhoven, The Netherlands, in 1978. From 1978 to 1983 he worked with Kema and from 1983 to 1998 with Sep. Since then he is with TenneT, the Dutch Transmission System Operator, as senior engineer for network planning and network strategy. Since 1993 he is a part-time Professor at the Delft University of Technoly and since 2000 he is also a part-time Professor in the Electric Power Systems Group at the Eindhoven University of Technology, the Netherlands. He is leading research programs on distributed generation, integration of wind power, network concepts and reliability.

Mr. Kling is involved in scientific organizations such as Cigre and IEEE. $\mathrm{He}$ is the Dutch Representative in the Cigre Study Committee C6 Distribution Systems and Dispersed Generation. 